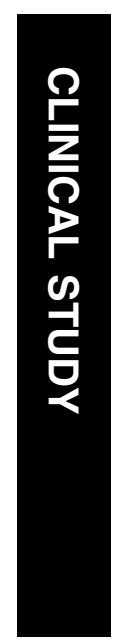

\title{
The influence of donor and recipient factors in allograft rejection of the human cornea
}

${ }^{1}$ Manchester Royal Eye Hospital, Lister Centre, Manchester, UK

${ }^{2}$ Department of Ophthalmology, Taipei Medical University Hospital, Taipei, Taiwan

${ }^{3}$ School of Clinical and Laboratory Science, University of Manchester, Manchester, UK

${ }^{4}$ School of Clinical Sciences, the University of Nottingham, Queens Medical Centre, Nottingham, UK

Correspondence: I Rahman, Department of Ophthalmology, Manchester Royal Eye Hospital, Lister Centre, Nelson Street, Manchester, M13 9WH, UK. Tel: 0161276 1234. Fax: 01612726618 . E-mail: imran1973@ tiscali.co.uk

Received: 24 March 2008 Accepted in revised form: 19 February 2009 Published online: 17 April 2009

Conflict of interest: None

\section{Abstract}

The health of the corneal endothelium is essential in maintaining the clarity of the transplanted human cornea. Immune-mediated endothelial rejection is a complex series of events, which may culminate in the decompensation of the donor button. It is the commonest instigator of failure in penetrating corneal transplantation. Methods This retrospective case note review of 203 penetrating keratoplasties with adequate follow-up data during a 5-year study period from 1 January 2000 to 31 December 2003 at Manchester Royal Eye Hospital, were used for analysis.

Results Forty-three of the 203 donor grafts underwent at least one single episode of immune-mediated endothelial rejection, an incidence of $21 \%$ over a 5-year follow-up. Recipient's age was inversely associated with the risk of rejection. The average age for the cohort of 58.7 years and average age for rejecting patients of 47.6 years were strongly significantly different $(P=0.009)$. Rejection in keratoconic patients accounted for $30 \%$ of cases. Death to enucleation time $(P=0.03)$ was also associated with an increased risk of rejection.

\section{Conclusion Although penetrating}

keratoplasty is an effective long-term treatment option for improving visual function, the endothelial rejection rate in our study was $21 \%$ over a mean follow-up of over 5 years. Host vascularisation, regrafts, younger recipient age group, and donor factors were found to be significantly associated with a risk of rejection. Rejection in keratoconic recipients was more common than expected. Eye (2010) 24, 334-339; doi:10.1038/eye.2009.72; published online 17 April 2009
I Rahman', MC Huang², F Carley', MC Hillarby³, GT Vasileiadis ${ }^{4}$ and A Tullo'

Keywords: penetrating keratoplasty; corneal graft; rejection; failure

Introduction

Penetrating keratoplasty (PK) is one of the most commonly performed types of transplantation in the UK. However, poor results may occur in unfavourable conditions. The 5-year overall graft-survival rate is estimated at $\sim 65 \%$, whereas survival is as high as $90 \%$ in some recipient groups. ${ }^{1-4}$

The integrity of the corneal endothelium is essential in maintaining graft clarity. Immunemediated endothelial rejection is a complex series of immunological events, which may culminate in the decompensation of the donor button. It is the most common cause of failure in corneal graft surgery. ${ }^{5,6}$ Rates of rejection range from 3.5 to $65 \%{ }^{5}$ depending on the case series.

The aim of this retrospective review of patients undergoing allograft endothelial rejection over a 5-year period in a major UK centre was to identify prognostic risk factors.

\section{Methods}

This retrospective case note review identified 203 patients with complete clinical records who had undergone PK during a 5-year study period from 1 January 2000 to 31 December 2003 at Manchester Royal Eye Hospital through the NHS Blood and Transplant National Transplant Database.

\section{Evaluation of preoperative risk factors}

All donor material was stored after retrieval in an UK Transplant Eye Bank for up to 28 days in organ culture at $34^{\circ} \mathrm{C}$. Donor-related factors studied were age, time from death to 
enucleation, length of time in storage, and endothelial cell count. Recipient-related factors included age; previous grafts; preoperative ocular conditions (glaucoma, inflammation, infection, ocular surface disease, and corneal vascularisation (number of quadrants of superficial and deep vascularisation)). Associated surgical procedures at the time of surgery, such as intraocular lens exchange or removal, vitrectomy or combined procedures were also documented.

\section{Surgical technique}

Corneal transplantation was carried out in all cases by one of the two grades of surgeon, consultant or corneal fellow. Donor corneas were inspected and then trephined using vacuum trephination (Barron Hessberg, Barron Precision Instruments, MI, USA) or non-vacuum trephine (Coronet Network Medical, Ripon, North Yorkshire, UK). Trephination of the recipient corneas were undertaken wherever possible using the vacuum trephine. The donor cornea was sutured to the recipient using 16 10/0 nylon interrupted sutures as a routine and subconjunctival antibiotic given in all cases. If required, vitrectomy was carried out using an automated motorised vitrectomy technique. Cataract extraction, if required, was carried out using an open sky/extracapsular technique after a can opener capsulorhexis. Soft lens matter was aspirated using manual Simco aspiration. Insertion of an intraocular lens was decided on a case-by-case basis.

Routine post-operative medication consisted of topical prednisolone acetate $1 \%$ four times a day combined with topical antibiotic. After discharge, the patient was seen weekly for 1 month, followed by monthly for 3 months, and then 4-6 monthly depending on the individual response. Typically, antibiotic was reduced over the subsequent post-operative month, and $1 \%$ prednisolone tapered down over 3 months with an eventual change to $0.5 \%$ prednisolone once daily lifelong. Clinical policy was to remove any remaining sutures after 1 year. After removal, steroids were increased to four times daily and reduced to once daily over 1 week with covering antibiotics.

Episodes of rejection were diagnosed on the basis of characteristics documented by Maumenee. ${ }^{32}$ Briefly, these were development of an endothelial rejection line; increased corneal thickness; or recent/concurrent anterior chamber reaction, or improvement of signs on intensive corticosteroid therapy.

In general, episodes of immunological endothelial graft rejection were treated with hourly prednisolone $1 \%$ for 1 week and reduced depending on the response (level 1 treatment). In severe cases, a single pulsed dose of IV methylprednisolone $500 \mathrm{mg}$ was used (level 2 treatment).

\section{Statistical analysis}

Statistical analysis was carried out using Graphpad Instat 3 (Version 3.06, Graphpad software Inc., San Diego, CA, USA). Statistical tests used included unpaired $t$-test, odds ratio, Fisher's exact test, and $\chi^{2}$-test.

\section{Results}

A summary of the indications for corneal grafting in these 43 patients is given in Table 1 . Of the 203 cases, 43 donor grafts underwent at least one episode of endothelial rejection, an incidence of $21 \%$ over a 5 -year follow-up. There were 13 female and 30 male patients in this group. The average follow-up for rejectors was 61 months ( $\mathrm{SD} \pm 12.2$ ), ranging from 38 to 81 months. The mean age of the rejection patient group was $48(\mathrm{SD} \pm 22)$, ranging from 8 to 91 years of age. Five of the 43 patients suffered a second rejection episode. Regrafts accounted for 9 cases $(21 \%)$. Eight of these were after earlier episodes of rejection, resulting in eventual corneal graft failure. Thirteen $(30 \%)$ occurred in patients with keratoconus, four (9\%) in Fuchs' dystrophy, and five $(12 \%)$ in pseudophakic corneal oedema. The remaining

Table 1 Indication for graft in patients with rejection episodes

\begin{tabular}{lcc}
\hline Indication for graft & $\begin{array}{c}\text { Number of } \\
\text { rejections } \\
\mathrm{n}=43 \\
\text { (\% of patients) }\end{array}$ & $\begin{array}{c}\text { Total number } \\
\text { of patients } \\
\mathrm{n}=203 \\
\text { (\% of patients) }\end{array}$ \\
\hline $\begin{array}{l}\text { Ectasia } \\
\text { KC }\end{array}$ & $13(30)$ & 48 \\
Dystophy & & $48(30)$ \\
FED & $4(9)$ & 28 \\
Other & $1(2)$ & $21(13)$ \\
Earlier ocular surgery & & 7 \\
PBK & $5(12)$ & 44 \\
Other & $1(2)$ & $37(23)$ \\
Infections & & $1(1)$ \\
Viral & $2(5)$ & 18 \\
Fungal & $1(2)$ & $8(5)$ \\
Other & $1(2)$ & $3(2)$ \\
Ulcerative keratitis & & $2(1)$ \\
RA & $1(2)$ & 11 \\
Other & $2(5)$ & $3(2)$ \\
Regrafts & & $8(5)$ \\
Rejection & & \\
High astigmatism & $1(2)$ & 41 \\
Opacification & $1(2)$ & $6(10)$ \\
Other & $2(5)$ & $6(4)$ \\
\hline KC, & & $7(4)$ \\
\hline
\end{tabular}

KC, keratoconus; FED, Fuchs' endothelial dystrophy; RA, rheumatoid arthritis; PBK, pseudophalic bullous keratopathy. 
13 cases consisted of four (9\%) infections, three $(7 \%)$ ulcerative keratitis, one (2\%) corneal opacification, one (2\%) dystrophy, one (2\%) high astigmatism, and three (7\%) others.

\section{Outcomes of rejection}

Figure 1 displays a Kaplan-Meier curve for rejection episodes. Of the 43 rejecting PKs, 37 episodes were treated with level 1 treatment protocol, and six with level 2. The median time from surgery to rejection was 10.5 months. Sixteen (38\%) of these individuals underwent eventual graft failure after rejection. The median time for failure after rejection was 12 months, median 17 months from surgery to eventual failure.

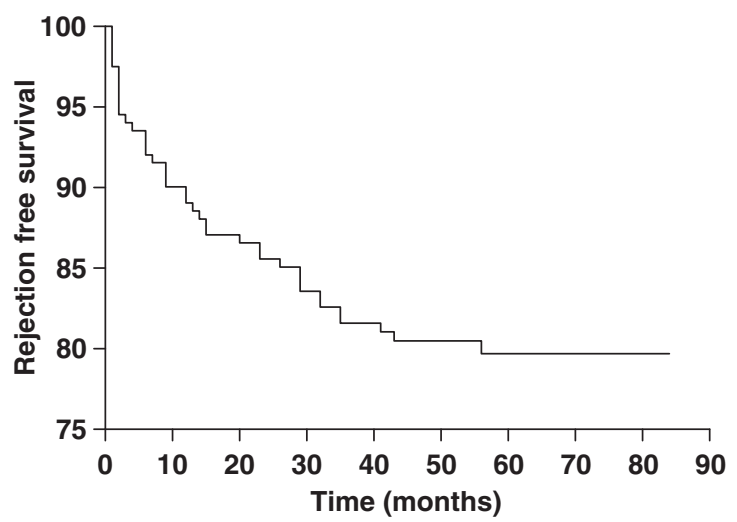

Figure 1 Kaplan-Meier curve to show the episodes of rejection in the study group $(n=203)$.

\section{Risk factors for rejection}

Comparing the rejecting group with the remainder of the cohort, we found vascularisation of the cornea was present in the recipient in $47 \%$ of cases, of which $30 \%$ was superficial and $17 \%$ was deep vascularisation. Analysis showed a risk of rejection with two or four quadrants of superficial, and with three or four quadrants of deep vascularisation was not statistically significant $(P=0.69)$. However, once rejection had occurred, the risk of eventual failure within vascularised grafts is highly significant $(P=0.02)$. Those patients undergoing regrafting for an earlier failed donor grafts after endothelial rejection were also prone to an increased risk of rejection of the new graft, resulting in eventual failure.

Risk factors are investigated and statistical analysis is outlined in Table 2. Additional surgical intervention at the time of surgery failed to add to the risk of rejection. Cataract extraction, intraocular lens removal, or insertion in the anterior chamber or posterior chamber did not increase the risk of rejection $(P=0.84)$.

\section{Donor risk factors}

Of the donor-related factors, death to enucleation time was statistically significant $(P=0.03)$ in relation to rejection. Donor age was found to be just outside statistical significance $(P=0.06)$. Death to enucleation time was not a significant factor in rejection. Donor size appeared to be important. A donor size $>8 \mathrm{~mm}$ compared with a donor $<8 \mathrm{~mm}$ were associated with the

Table 2 Factors associated with risk of rejection

\begin{tabular}{|c|c|c|c|}
\hline & Graft rejection & Non-rejection patients & P-value \\
\hline Donor patients & $\mathrm{n}=43$ & $\mathrm{n}=160$ & \\
\hline Mean age (years) & $52.7(\mathrm{SD} \pm 17.5)$ & $59.5(\mathrm{SD} \pm 17.2)$ & 0.06 \\
\hline Death-enucleation (hrs) & 17.5 & 14.8 & 0.03 \\
\hline Storage time (days) & 18 & 19.5 & 0.08 \\
\hline \multicolumn{4}{|l|}{ Recipient factors } \\
\hline Mean recipient age (years) & $47.6(\mathrm{SD} \pm 22)$ & $58.7(\mathrm{SD} \pm 21.7)$ & 0.009 \\
\hline Inflammation (number ( $\%$ of patients)) & $12(28)$ & $33(20)$ & 0.30 \\
\hline Infection (number (\% of patients)) & $4(9)$ & $18(11)$ & 0.57 \\
\hline Glaucoma (number (\% of patients)) & $5(12)$ & $23(14)$ & 0.21 \\
\hline Ocular surface disease (number (\% of patients)) & $5(12)$ & $26(16)$ & 0.33 \\
\hline Vascularisation (number ( $\%$ of patients)) & $22(51)$ & $72(45)$ & 0.69 \\
\hline \multicolumn{4}{|l|}{ Additional procedures } \\
\hline $\begin{array}{l}\text { Cataract extraction, IOL removal or implantation of } \\
\text { IOL (number ( } \% \text { of patients)) }\end{array}$ & $9(21)$ & $45(22)$ & 0.84 \\
\hline Vitrectomy (number ( $\%$ of patients)) & $2(5)$ & $12(7)$ & 0.94 \\
\hline \multicolumn{4}{|l|}{ Graft size } \\
\hline$\geqslant 8 \mathrm{~mm}$ (number (\% of patients)) & $35(83)$ & $110(68)$ & 0.06 \\
\hline$<8 \mathrm{~mm}$ (number (\% of patients)) & $7(16)$ & $52(32)$ & \\
\hline
\end{tabular}


Table 3 Subcategorisation of age as a risk factor for rejection

\begin{tabular}{lcr}
\hline Age group & $\begin{array}{c}\text { Number of patients } \\
\mathrm{n}=203 \text { (\% of patients) }\end{array}$ & $\begin{array}{c}\text { Number of rejections } \\
\mathrm{n}=43 \text { (\% of patients) }\end{array}$ \\
\hline 30 or less & $37(18)$ & $13(30)$ \\
$31-50$ & $42(21)$ & $5(12)$ \\
51 and over & $124(61)$ & $25(28)$ \\
\hline
\end{tabular}

risk of rejection. However, this was again just outside statistical significance $(P=0.06)$.

\section{Age as a risk factor}

Younger recipient age was strongly associated with the risk of rejection, with the average age for the cohort 58.7 years, and average age for rejected patients of 47.6 years $(P=0.009)$. Subcategorising the age groups further shows that there were $37(18 \%)$ patients $\leqslant 30$ years at the time of grafting, $13(30 \%)$ of these experienced a rejection episode. The majority in this group were keratoconics. Further, of the $42(21 \%)$ patients between the ages of 31 and 50 inclusive, only five (12\%) suffered an episode of rejection. Of the remainder $124(61 \%)$ patients aged 51 and over, 25 (58\%) episodes of rejection were noted. This age difference was a significant factor in rejection episodes $(P=0.04)$. Summaries of all the results are given in Tables 1-3.

\section{Rejection and keratoconus}

Subgroup analysis showed that keratoconics accounted for $30 \%$ of all cases of rejection. The mean age of the keratoconic recipients was less than the remainder of the cohort of 43 rejecting patients, 26.7 years compared with an average of 47.6 years $(P=0.001)$. Both groups had a similar mean rejection time of 15 months after PK and comparable death to enucleation time of the donor at 18 hours. Rejection in keratoconics resulted in immunologically mediated failure in only three of the 13 patients (23\%), compared with rejection in other forms of graft in which 13 out of $30(43 \%)$ failed. This was not statistically significant $(P=0.31)$. However, no keratoconic patient's graft failed in our study in the absence of rejection.

\section{Discussion}

Penetrating keratoplasty is an effective long-term treatment option for improving visual function in selected patients with corneal opacification. However, to optimise graft survival and limit rejection episodes, it is important to establish the associations and the time course of graft rejection. The overall endothelial rejection rate in our study was as high as $21 \%$ over a mean followup of over 5 years, and an estimated $7.4 \%$ of all PKs in this study period suffered eventual graft failure after an episode of rejection.

Most graft rejections occur in the first 3 years after keratoplasty. ${ }^{18}$ Our median time of rejection was 10.5 months after PK, in keeping with the results of Alldredge et $a l^{19}$ and Peleyer et $a l^{18}$ who noted that rejection episodes were recognised most frequently over the first 12 months, 29 and $43 \%$, respectively. Their rates of rejection, on the other hand, were higher than our findings, which were similar to that of Ing et al, ${ }^{20}$ who over a 10-year period documented a cumulative

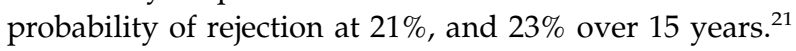
This may represent a difference in case mix, relatively lower levels of high-risk grafts, and the inclusion of endothelial rejection only in our series.

Abbott et $a l^{15}$ showed that endothelial cell loss occurs at the time of surgery and in the subsequent 3 years postoperatively, with a chronic cell-loss rate of 2.6-7.8\% per year. ${ }^{16,17}$ This is further exacerbated in endothelial rejection episodes in which a sizeable proportion of endothelial cells is lost. In some cases of rejection, the endothelial cell loss is so profound that the remaining limited insufficient endothelial cell numbers are unable to maintain graft clarity. Prompt diagnosis and adequate therapy may call a halt to the rejection episode and maintain graft clarity. Claerhout et $a^{34}$ supported this point by reporting that delays in diagnosis and treatment of rejection were the most important factor in the extent of endothelial loss.

Several risk factors in recipients for corneal graft rejection have become well established and are useful in assessing prognosis before surgery.

Rejection episodes in keratoconic patients appear to be common in our study, accounting for $30 \%$ of overall cases of rejection, although only $23 \%$ of these proceed to failure. In 1974, Chandler and Kaufman ${ }^{24}$ reported a high incidence of $35 \%$. Sharif and Casey ${ }^{7}$ documented a rate of $21 \%$. Others, however, have stated far lower rates varying between 6 and 13\%..$^{25-27}$ This may reflect changes in surgical technique and post-operative management over the years, although not shown in our present study. More intriguingly, most studies agree on the documented relatively low rate of failure after an episode of rejection in keratoconics. ${ }^{28}$

It might be expected that atopic patients are at a greater risk of ocular inflammation because of the release of inflammatory mediators. Recent evidence shows atopic dermatitis to be a statistically significant risk factor for corneal graft rejection. ${ }^{29}$ Hargrave et $a l^{30}$ hypothesised an alternative mechanism accounting for the higher incidence of rejection, but low risk of failure in keratoconics. Using animal models and histology of failed grafts a Th2-mediated mechanism of rejection was suggested. Beauregard et $a l^{33}$ described the role of Th1 
and Th2 cells working together to instigate rejection. Using mouse models of atopic conjunctivitis, they found an enhanced systemic Th2 response to donor corneal cells and a more rapid onset of rejection without the direct infiltration of the host with esoinophils. The Th2 response is, therefore, perceived to originate as a systemic rejection as opposed to a local effect. This theory, although unproven, offers an explanation to the unusual phenomenon of rejection seen in keratoconics. Ohguro et $a l^{31}$ suggested that the rejection episode affected both the donor and recipient, explained by the non-specific and specific immune responses. The specific immune response affected donor endothelium and a wider non-specific response affecting both the donor and recipient.

Other possibilities consistent with our findings point to age being an important characteristic in keratoconics as most patients are under 40 . We have shown that within the context of keratoconus, those under the age of 30 are statistically more likely to reject. This may reflect a more active immune response in younger individuals. Younger patients may also present earlier because of the intensity of the immune response, and hence limit endothelial damage. Older patients may, on the other hand, show a more prolonged, possibly subclinical rejection with a greater degree of endothelial cell death resulting in eventual endothelial failure. This suggests that undiagnosed immune reactions may have contributed to 'endothelial failure' in other eyes. Alternatively, relatively healthy high-density recipient's residual endothelium, as present in keratoconics, may simply allow migration of endothelial cells to central damaged areas of endothelium, acting as a potential 'reserve' of endothelial cells.

Corneal blood vessels are responsible for the afferent pathway of allograft immune response. For this reason immune reactions are more common in the presence of corneal neovascularisation. In terms of rejection, corneal neovascularisation has been reported as a strong risk factor. ${ }^{11-13}$ However, we did not find a significant correlation between corneal vascularisation and rejection, irrespective of whether these were deep or superficial $(P=0.69)$. When rejection had occurred, the presence of vascularisation was, however, significant in resulting in the eventual failure of the transplant $(P=0.02)$,

suggesting the treatment of rejection in this setting may be hindered by the vascularisation.

Our findings, however, are in contrast with those of others who have studied the role of corneal vascularisation. Thompson $e t \mathrm{al}^{3}$ found a 65\% 10-year survival rate for corneal grafts associated with deep stromal vessels. Vail et $a l^{14}$ documented a significantly higher rate of rejection in eyes with deep vascularisation, although not associated with the number of quadrants affected. It is difficult to clearly define the reason for the non-significant correlation between vascularisation and rejection in our study. The retrospective nature of the study and the variation of cases will inevitably have a large bearing on this through variability of documentation and the case mix studied.

In our study we noted an increased risk of rejection in grafts $>8 \mathrm{~mm}$. This increased risk of rejection in larger donor grafts has been reported by others at $8.5 \mathrm{~mm}$ or above. ${ }^{7,8}$ Tuft et $a l^{9}$ described an increased risk of rejection in grafts $>7.5 \mathrm{~mm}$. Conversely, Maguire et $a l^{10}$ found a greater risk of rejection in grafts $<8 \mathrm{~mm}$, supporting the findings of Sanfilippo et al. ${ }^{11}$ Generally, a larger donor transplant will be positioned closer to the limbal region, and thus prone to the antigen/antibody influences of the limbal vasculature of the foreign donor antigens. Larger grafts are, therefore, more at 'risk' of endothelial rejection.

Donor-related factors on the potential outcome have been rarely identified in the literature. Our findings that donor age $(P=0.06)$ increasing death to enucleation time $(P=0.03)$ are associated with significant or close to significant increased risk of rejection. Patel et $a l^{21}$ stated that late failure was associated with higher recipient age and lower endothelial cell density. Williams et $a l^{22}$ showed only a weak correlation with donor age and eventual failure with older donor corneas. Conversely, Borderie $e t a l^{23}$ found relative risk of failure to be 4.3 in recipients with donor corneas under the age of 80 years, but no influence on post-operative endothelial cell density. The reasoning for death to enucleation time as a significant factor in the influence of rejection is uncertain and remains unsubstantiated.

\section{Summary}

Although corneal transplantation remains a successful form of transplantation, rejection of the donor cornea is a frequent complication and remains the most common cause of failure. We found a rejection rate of $21 \%$ over a 5-year follow-up. Recipient risk factors included a younger age group and keratoconus, whereas donor factors, including donor age, donor size, and death to enucleation time were associated with rejection.

\section{Acknowledgements}

We would like to acknowledge UK Transplant, in particular Mark Jones, for their ongoing support. We would also like to thank the Eye Bank team and administration staff at the Manchester Royal Eye Hospital in providing advice, support, and assistance, and in particular Dr David Haider, for his assistance in data collection. 


\section{References}

1 Williams KA, Roder D, Esterman A, Muehlberg SM, Coster DJ. Factors predictive of corneal graft survival. Report from the Australian Corneal Graft registry. Ophthalmology 1992; 99: 403-414.

2 Sugar A. An analysis of corneal endothelial and graft survival in pseudophakic bullous keratopathy. Trans Am Ophthalmol Soc 1989; 87: 762-801.

3 Thompson RW, Price MO, Bowers PJ, Price Jr FW. Long term graft survival after penetrating keratoplasty. Ophthalmology 2003; 119: 1398-1402.

4 The collaborative corneal transplantation studies research group. The collaborative corneal transplantation studies (CCTS). Effectiveness of histocompatibility matching in high risk corneal transplantation. Arch Ophthalmol 1992; 110: 1392-1403.

5 Khodadoust AA. The allograft rejection reaction: the leading cause of late failure of clinical corneal grafts. Ciba Found Symp 1973; 15: 151-164.

6 Patel SV, Hodge DO, Bourne WM. Corneal endothelium and postoperative outcomes 15 years after penetrating keratoplasty. Am J Ophthalmol 2005; 139: 311-319.

7 Sharif KW, Casey TA. Penetrating Keratoplasty for keratoconus: complications and long term success. $\mathrm{Br} \mathrm{J}$ Ophthalmol 1991; 75: 142-146.

8 Williams KA, Muehlberg SM, Wing SJ. The Australian Corneal graft registry: 1990 to 1992 report. Aust NZ J Ophthalmol 1993; 21: 1-48.

9 Tuft SJ, Gregory WM, Davison CR. Bilateral penetrating keratoplasty for keratoconus. Ophthalmology 1995; 102: 462-468.

10 Maguire MG, Stark WJ, Gottsch JD, Stulting RD, Sugar A, Fink NE et al. Risk factors for corneal graft failure and rejection in the collaborative corneal transplantation studies. Ophthalmology 1994; 101: 1536-1547.

11 Sanfilippo F, MacQueen JM, Vaughn WK, Foulks GN. Reduced graft rejection with good HLA-A and B matching in high risk corneal transplantation. $N$ Engl J Med 1986; 315: 29-35.

12 Dandona L, Naduvilath TJ, Janarthanan M, Ragu K, Rao GN. Survival analysis and visual outcome in a large series of corneal transplants in India. Br J Ophthalmol 1997; 81: 726-731.

13 Price Jr FW, Whitson WE, Collins KS, Marks RG. Five year corneal graft survival. A large, single centre patient cohort. Arch Ophthalmol 1993; 111: 799-805.

14 Vail A, Gore SM, Bradley BA, Easty DL, Rogers CA. Corneal graft survival and visual outcome. A multicentre study. Ophthalmology 1994; 101: 120-127.

15 Abbott RL, Fine M, Guillet E. Long-term changes in corneal endothelium following penetrating keratoplasty: a specular microscopic study. Ophthalmology 1983; 90: 676-681.

16 Zacks CM, Abbott RL, Fine M. Long term changes in endothelium after keratoplasty. A follow up study. Cornea 1990; 9: 92-97.
17 Bourne WM, Hodge DO, Nelson LR. Corneal endothelium five years after transplantation. Ophthalmology 1994; 118: 186-196.

18 Pleyer U, Steuhl KP, Weidle EG, Lisch W, Thiel HJ. Corneal graft rejection: incidence, manifestation, and interaction of clinical subtypes. Transplant Proc 1992; 24: 2034-2037.

19 Alldredge OC, Krachmer JH. Clinical types of corneal transplant rejection. Their manifestations, frequency, preoperative correlates and treatment. Arch Ophthalmol 1981; 99: 599-604.

20 Ing JJ, Ing HH, Nelson LR, Hodge DO, Bourne WM. Ten year postoperative results of penetrating Keratoplasty. Ophthalmology 1998; 105: 1855-1865.

21 Patel SV, Hodge DO, Bourne WM. Corneal endothelium and postoperative outcomes 15 years after penetrating keratoplasty. Am J Ophthalmol 2005; 139: 311-319.

22 Williams KA, Esterman AJ, Bartlett C, Holland H, Hornsby NB, Coster DJ. How effective is penetrating corneal transplantation? Factors influencing long-term outcome in multivariate analysis; on behalf of all contributors to the Australian corneal graft registry. Transplantation 2006; 81: 896-901.

23 Borderie VM, Scheer S, Touzeau O, Vedie F, CarvajalGonzalez S, Laroche L. Donor organ cultured corneal tissue selection before penetrating keratoplasty. $\mathrm{Br} J$ Ophthalmol 1998; 82: 382-388.

24 Chandler JW, Kaufmann HF. Graft rejections after keratoconus. Am J Ophthalmol 1974; 77: 543-547.

25 Trautman RC, Lambers MA. Penetrating keratoplasty for keratoconus. Cornea 1987; 6: 289-305.

26 Keates RH, Falkenstein S. Keratoplasty in keratoconus. Am J Ophthalmol 1972; 74: 442-444.

27 Anseth A. Keratoplasty for keratoconus: a report of 50 cases. Acta Ophthalmol 1967; 45: 684-687.

28 Kirkness CM, Flicker LA, Steele McG. The success of penetrating keratoplasty for keratoconus. Eye 1990; 4: 673-688.

29 Reinhard T, Moller M, Sundmacher R. Penetrating keratoplasty in patients with atopic dermatitis with and without systemic cyclosporin A. Cornea 1999; 18: 645-651.

30 Hargrave S, Chu Y, Mendelblatt D, Mayhew E, Niederkorn J. Preliminary findings in corneal allograft rejection in patients with keratoconus. Am J Ophthalmol 2003; 135: 452-460.

31 Ohguro N, Matsuda M, Shimomura Y, Inoue Y, Tano Y. Effects of penetrating keratoplasty rejection on the endothelium of the donor cornea and the recipient peripheral cornea. Am J Ophthalmol 2000; 129: 468-471.

32 Maumenee AE. Clinical aspects of the corneal homograft reaction. Invest Ophthalmol 1962; 1: 244-252.

33 Beauregard C, Stevens C, Mayhew E, Niederkorn JY. Cutting Edge: atopy promotes Th2 responses to alloantigens and increases the incidence and tempo of corneal allograft rejection. J Immunol 2005; 174: 6577-6581.

34 Claerhout I, Beele H, DeBacquer D, Kestelyn P. Factors influencing the decline in endothelial cell density after corneal allograft rejection. Invest Ophthalmol Vis Sci 2003; 44: $4747-4752$. 